\title{
RACIONALIDADE COLETIVA NO STF E \\ PRECEDENTES VINCULANTES: O EXEMPLO DO CONCEITO DE VIDA NA ADPF N. 54
}

\author{
COLLECTIVE RATIONALITY IN THE BRAZILIAN CONSTITUTIONAL COURT AND BINDING \\ PRECEDENTS: THE EXAMPLE OF THE CONCEPT OF LIFE IN ADPF NO. 54
}

\section{RACIONALIDAD COLECTIVA EN EL STF Y PRECEDENTES VINCULANTES: EL EJEMPLO DEL CONCEPTO DE VIDA EN LA ADPF N. 54}

\section{Flavia Portella Püschel ${ }^{1}$}

Licença CC BY:

Artigo distribuído sob os termos Creative Commons, permite uso e distribuição irrestrita em qualquer meio desde que o autor credite a fonte original.

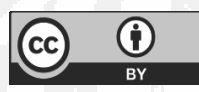

\begin{abstract}
Resumo: Objetivo deste artigo é explicitar a relação entre o procedimento de agregação das posições individuais dos ministros para composição dos acórdãos do Supremo Tribunal Federal (STF) e o modo como tais acórdãos devem ser considerados para a constituição de precedentes judiciais vinculantes. A hipótese que se investiga, com base na teoria dos agentes coletivos de Christian LIST e Philip PETTIT, é que o sistema de votação por maioria, como empregado pelo STF, é incapaz de garantir fundamentos racionais coletivos para as decisões da corte e que tal característica institucional é de fundamental importância para o desenvolvimento de uma teoria brasileira do precedente. Conclui-se que, por falta de fundamento racional coletivo, nem toda decisão do STF constitui precedente, ainda que o julgamento tenha sido unânime, e que o estabelecimento da própria regra de precedente, nos casos em que ela exista, é um desafio que não pode ser superado sem análise dos fundamentos de todos os votos. O modo como o STJ empregou a decisão da ADPF n. 54 é evidência de que tais preocupações não são sempre reconhecidas, o que cria um risco de seleção arbitrária de posições individuais em casos já julgados e de aumento da fragmentação jurisprudencial.
\end{abstract}

Palavras-chave: Racionalidade coletiva; Precedentes vinculantes; Decisões judiciais colegiadas; Supremo Tribunal Federal; Novo Código de Processo Civil.

Abstract: This article argues that the relationship between the way in which the judgements of the Justices of the Brazilian Constitutional Court are grouped together cannot guarantee collective rationality of court rulings, an institutional characteristic that poses challenges for the unification of the law by means of precedents. The problem is presented based on the example of ADPF no. 54, a ruling on anencephaly and its use as a precedent by the Brazilian Supreme Federal Court of Justice.

1 Doutora em Direito Civil pela Universidade de São Paulo (USP), Professora Associada da Escola de Direito de São Paulo da Fundação Getulio Vargas (FGV Direito SP), São Paulo, S.P., Brasil. E-mail: flavia.puschel@fgv.br. A autora gostaria de agradecer aos participantes do Workshop de Pesquisas da FGV Direito SP, aos participantes da sessão "Courts and Problem-Solving Courts: Decisions, Due Process and Efficiency", do " 2015 Law and Society Association Annual Meeting", realizado em Seattle, bem como aos avaliadores anônimos desta revista, pelos comentários a versões anteriores deste trabalho, os quais permitiram o seu aperfeiçoamento. Agradecimentos são devidos também a Ricardo Savignani Álvares Leite, por seu auxílio no levantamento bibliográfico e na formatação do texto. 
The argument is based on the theory of collective agents of Christian List and Philip Pettit and the system of majority vote, as used by the Supreme Federal Court, which is not capable of guaranteeing collective rational fundamentals for the decisions of the court, and on the idea that this institutional characteristic is fundamentally important for the development of a Brazilian theory of precedent. The article concludes that due to the lack of collective rationality, not every ruling by the Constitutional Court can be considered a precedent, and that to establish a precedent, it is necessary to analyze all the individual opinions. The way in which the Superior Court of Justice applied the ruling in ADPF no. 54 as a precedent shows that these questions were not adequately taken into account, which creates a risk of arbitrary selection of individual opinions, and of further fragmentation of court rulings.

Key-words: Collective Rationality; Binding Precedents; Collegial Court Rulings; Brazilian Constitutional Court; New Brazilian Civil Procedure Code.

Resumen: El objetivo de este artículo es explicitar la relación entre el procedimiento de agregación de las posiciones individuales de los ministros para la composición de los acuerdos del Supremo Tribunal Federal (STF) y el modo como tales acuerdos deben ser considerados para la constitución de precedentes judiciales vinculantes. La hipótesis que se investiga, con base en la teoría de los agentes colectivos de Christian LIST y Philip PETTIT, es que el sistema de votación por mayoría, como empleado por el STF, es incapaz de garantizar fundamentos racionales colectivos para las decisiones de la corte y que tal característica institucional es de fundamental importancia para el desarrollo de una teoría brasileña precedente. Se concluye que, por falta de fundamento racional colectivo, ni toda decisión del STF constituyó precedente, aún que la sentencia haya sido unánime, y que el estabelecimiento de la propia regla de precedente, en los casos en que ella exista, es un desafío que no puede ser superado sin análisis de los fundamentos de todos los votos. El modo como el STJ empleó la decisión de la ADPF n. 54 es evidencia de que tales preocupaciones no son siempre reconocidas, lo que crea un riesgo de selección arbitraria de posiciones individuales en casos ya juzgados y de aumento de la fragmentación jurisprudencial.

Palabras - clave: Racionalidad colectiva; Precedentes vinculantes; Decisiones judiciales colegiadas; Supremo Tribunal Federal; Nuevo Código de Proceso Civil.

\section{INTRODUÇÃO}

A partir da Reforma do Judiciário realizada pela Emenda Constitucional $\mathrm{n}$. 45 , de 2004, adotou-se uma agenda "centralizadora e racionalizadora" como estratégia para busca de segurança jurídica e previsibilidade das decisões judiciais², a qual recentemente se desdobrou na valorização de "estímulos para que a jurisprudência se uniformize, à luz do que venham a decidir tribunais superiores e até de segundo grau" pelo Código de Processo Civil de 2015 (CPC) 2.

2 GROSS CUNHA, Luciana e ALMEIDA, Frederico de. Justiça e desenvolvimento econômico na Reforma do Judiciário brasileiro. In: SCHAPIRO, Mario G. e TRUBEK, David M. Direito e Desenvolvimento: Um diálogo entre os BRICS. São Paulo: Saraiva, 2012, p. 361 e 365.

3 BRASIL. Congresso Nacional. Senado Federal. Comissão de Juristas Responsável pela Elaboração de Anteprojeto de Código de Processo Civil. Código de Processo Civil: anteprojeto. Brasília: Senado Federal, Presidência, 2010, p. 17. 
O novo Código de Processo Civil parece ter aproximado o direito brasileiro da tradição de Common Law $^{4}$, com seu uso de precedentes ${ }^{5}$. De fato, o art. 489, § $1^{\circ}$, VI do CPC determina que não se considera fundamentada - sendo, portanto, nula nos termos do art. 11 da mesma lei - a decisão judicial que "deixar de seguir enunciado de súmula, jurisprudência ou precedente invocado pela parte, sem demonstrar a existência de distinção no caso em julgamento ou a superação do entendimento" (grifo nosso).

Além disso, o art. 927 do CPC estabelece que "osjuízes e os tribunais observarão" (grifo nosso) as decisões do STF em controle concentrado de constitucionalidade, os acórdãos em incidente de assunção de competência ou de resolução de demandas repetitivas e em julgamento de recursos extraordinário e especial repetitivos, bem como a orientação do plenário ou do órgão especial aos quais estiverem vinculados, além das súmulas do STF e do Superior Tribunal de Justiça (STJ). O objetivo deste artigo é explicitar a relação entre o procedimento de agregação das posições individuais dos Ministros para composição dos acórdãos do Supremo Tribunal Federal (STF) e o modo como tais acórdãos devem ser considerados para a constituição de precedentes judiciais vinculantes. A hipótese que se investiga, com base na teoria dos agentes coletivos de Christian List e Philip Pettit ${ }^{6}$, é que o sistema de votação por maioria, como empregado pelo STF, é incapaz de garantir fundamentos racionais coletivos para as decisões da corte e que tal característica institucional é de fundamental importância para o desenvolvimento de uma teoria brasileira do precedente.

Não há na doutrina posição pacífica a respeito do grau de obrigatoriedade estabelecido pelo art. 927 CPC. Marinoni, Arenhart e Mitidiero ${ }^{7}$ entendem que tal artigo "consagra a necessidade de stare decisis vertical no sistema jurídico

$4 \quad$ MANCUSO, Rodolfo de Camargo. O direito brasileiro segue filiado (estritamente) à família Civil Law? In: O Novo Código de Processo Civil: Questões Controvertidas. São Paulo: Atlas, 2015, p. 418.

5 Não se quer dizer com isso que o direito brasileiro tenha simplesmente "importado" a tradição de precedentes dos sistemas de Common Law (os quais, aliás, diferem também entre si). Trata-se da criação de um sistema de "precedentes à brasileira". Nesse sentido, cf. BUENO, Cassio Scarpinella. Novo Código de Processo Civil anotado. São Paulo: Saraiva, 2015, p. 567; THEODORO Jr., Humberto, NUNES, Dierle, BAHIA, Alexandre Melo Franco e PEDRON, Flávio Quinaud. Novo CPC: Fundamentos e sistematização. Rio de Janeiro: Forense, 2016, p. 405). Objetivo deste texto é, justamente, contribuir para a formação da versão brasileira do precedente. Não obstante, é inegável que a tradição de Common Law serviu como referência, tanto para o legislador quanto para os comentadores do novo CPC.

6 LIST, Christian e PETTIT, Philip. Aggregating Sets of Judgments: an Impossibility Result. In: Economics and Philosophy, Cambridge, v. 18, passim. 2002.

7 MARINONI, Luiz Guilherme, ARENHART, Sérgio Cruz e MITIDIERO, Daniel. Novo Código de Processo Civil comentado. São Paulo: RT, 2015, p. 873. 


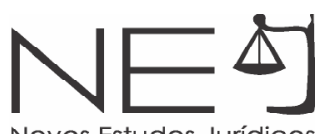

brasileiro". Segundo esses autores ${ }^{8}$, os precedentes do STF (seja em controle constitucional abstrato ou em controle difuso) e do STJ "não podem deixar de ter força obrigatória perante os demais juízes e tribunais". A força vinculante dos precedentes dos tribunais superiores seria a contrapartida do incremento do poder judicial em nosso sistema, além de que seria "completamente irracional o sistema que possui Cortes Supremas para definir o sentido da lei federal e da Constituição e, ainda assim, convive com decisões discrepantes dos tribunais ordinários".

No outro extremo, há quem entenda que - com exceção dos enunciados de súmula vinculante (CPC, art. 927, II), para cuja força obrigatória há previsão constitucional expressa - a vinculação prevista pelo art. 927 do CPC é "de inconstitucionalidade flagrante" 9. Para esses autores, os enunciados previstos nos incisos III a V do art. 927 do CPC teriam força apenas persuasiva. Cruz e Tucci defendem uma gradação da força vinculante dos precedentes, identificando precedentes com eficácia vinculante, com relativa eficácia vinculante e precedentes com eficácia meramente persuasivava. Wambier, Conceição, Ribeiro e Mello também defendem a gradação da força dos precedentes, classificada em obrigatoriedade forte, média e fraca10. Por outro lado, há também quem se manifesta pela inexistência de gradação da força vinculante entre as hipóteses do art. 927 do CPC11.

Para os objetivos deste trabalho, não é necessário tomar partido quanto a essa discussão, o que, ademais, demandaria análise mais aprofundada do que seria possível fazer aqui. Importa mostrar a existência de divergência doutrinária, uma vez que, conforme se tratará adiante, quanto maior a força vinculante atribuída aos precedentes, maior é a relevância das peculiaridades do sistema de votação por maioria.

8 MARINONI, Luiz Guilherme, ARENHART, Sérgio Cruz e MITIDIERO, Daniel. Novo curso de Processo Civil, vol. 1, 2. ed. São Paulo: RT, 2016, p. 147.

9 NERY Jr., Nelson e NERY, Rosa Maria de Andrade. Comentários ao Código de Processo Civil. São Paulo: RT, 2015, p. 1837. Também no sentido da inconstitucionalidade da força vinculante nos casos dos incisos III a $V$ do art. 927 do CPC manifesta-se CRUZ e TUCCI, José Rogério. In: BUENO, Cassio (Org.). Comentários ao Código de Processo Civil. Vol. 4. São Paulo: Saraiva, 2017, p. 30.

10 WAMBIER, Teresa Arruda Alvim, CONCEIÇÃO, Maria Lúcia Lins, RIBEIRO, Leonardo Ferres da Silva e MELLO, Rogerio Licastro Torres de. Primeiros comentários ao novo Código de Processo Civil. São Paulo: RT, 2015, p. 1317-1318.

11 BUENO, Cassio Scarpinella. Novo Código de Processo Civil anotado, p. 572. 
O problema é que a lei brasileira não estabelece o que se deve considerar como precedente, nem como deve servir para vincular (seja em maior ou menor grau) decisões posteriores, deixando em aberto como lidar com decisões judiciais que não tenham fundamento racional coletivo.

A questão da relação entre procedimento de agregação de votos e racionalidade coletiva será apresentada com base no exemplo da decisão do STF na Arguição de Descumprimento de Preceito Fundamental n. 54 (ADPF n. 54), a qual tratou da interrupção de gravidez em caso de feto anencefálico, e de seu uso como precedente para a decisão do Recurso Especial n. 1467888 (REsp n. 1467888) pelo Superior Tribunal de Justiça (STJ). Mais especificamente, usar-se-á como exemplo o papel do conceito jurídico de vida nas decisões da ADPF n. 54 e do REsp n. 1467888. A análise deste caso recente de aplicação de precedente permitirá esclarecer os riscos decorrentes da adoção de uma teoria do precedente que não leve em conta a relação entre o procedimento de votação por maioria e a formação de racionalidade coletiva.

A descrição do resultado da ADPF n. 54 e de três votos exemplares das diferentes posições sobre a vida do feto anencefálico presentes no acórdão será objeto da primeira parte do texto. Na segunda parte, tratar-se-á do problema da formação de racionalidade coletiva a partir da racionalidade individual, com base na teoria de Christian List e Philip Pettit ${ }^{12}$. Em seguida, serão mostrados os desafios que o procedimento de agregação de votos do STF impõe para a adoção de um sistema de precedentes vinculantes, tomando como exemplo a decisão do REsp n. 1467888, caso em que o STJ invocou o julgamento da ADPF n. 54 como precedente. Finalmente, o artigo será concluído com a generalização das constatações feitas com base na ADPF n. 54 e as consequências disso para o projeto de unificação da interpretação constitucional por meio de precedentes (mais ou menos) vinculantes.

A ADPF N. 54

A ADPF n. 54 foi proposta pela Confederação Nacional de Trabalhadores na Saúde (CNTS) em 2004, com o objetivo de obter do STF a declaração de ser

12 LIST, Christian e PETTIT, Philip. Aggregating Sets of Judgments: an Impossibility Result. In: Economics and Philosophy, Cambridge, v. 18, passim. 2002. 
"inconstitucional, com eficácia erga omnes e efeito vinculante ${ }^{13 "}$, a interpretação dos arts. 124, 126 e 128, I e II do Código Penal (CP):

(...) como impeditivos da antecipação terapêutica do parto em casos de gravidez de feto anencefálico, diagnosticados por médico habilitado, reconhecendo-se o direito subjetivo da gestante de se submeter a tal procedimento sem a necessidade de apresentação prévia de autorização judicial ou qualquer outra forma de permissão específica do Estado. ${ }^{14}$

O STF, por maioria de votos, julgou a ação procedente, em decisão datada de 12 de abril de $2012^{15}$. Foram vencidos os Ministros Ricardo Lewandowski e Cezar Peluso, que a julgavam improcedente. O Ministro Dias Toffoli não participou do julgamento, por estar impedido.

\section{O CONCEITO DE VIDA COMO PRESSUPOSTO: CONCORDÂNCIAS E DISCORDÂNCIAS}

Como afirmou o Ministro Celso de Mello ${ }^{16}$, o julgamento da ADPF n. 54 é histórico, pelo fato de que nela se discutem "o alcance e o sentido da vida e da morte" no direito brasileiro. De fato, embora o pedido não se refira diretamente ao conceito de vida, uma concepção sobre o que seja vida no direito brasileiro foi pressuposto do argumento de fundamentação da decisão acerca da licitude/ ilicitude da interrupção de gestação de feto anencefálico nos votos de todos os Ministros que participaram do julgamento ${ }^{17}$.

13 BARROSO, Luis Roberto. Petição inicial na ADPF n. 54, p. 22. Disponível em: <http://redir.stf.jus.br/ estfvisualizadorpub/jsp/consultarprocessoeletronico/ConsultarProcessoEletronico.jsf?seqobjetoinciden te=2226954>. Acesso em: 12 de fevereiro de 2014.

14 BARROSO, Luis Roberto. Petição inicial na ADPF n. 54, p. 22.

15 BRASIL. STF (Plenário). ESTADO - Laicidade. O Brasil é uma república laica, surgindo absolutamente neutro quanto às religiões. Considerações. Feto anencéfalo - Interrupção da gravidez - Mulher - Liberdade sexual e reprodutiva - Saúde - Dignidade - Autodeterminação - Direitos fundamentais - Crime - Inexistência. Mostra-se inconstitucional interpretação de a interrupção da gravidez de feto anencéfalo ser conduta tipificada nos artigos 124, 126 e 128, incisos I e II, do Código Penal. ADPF n. 54. Relator: Ministro Marco Aurélio. J. em 12/04/2012, p. 314. Disponível em: <http://redir.stf.jus.br/paginadorpub/paginador.jsp?docTP=TP\&doclD=3707334>. Acesso em: 23 de outubro de 2013.

16 BRASIL. STF (Plenário). ADPF n. 54, p. 314.

17 sto não significa que todos os Ministros tenham discutido expressamente o conceito de vida em seus votos. $O$ que se afirma é que alguma concepção de vida é pressuposto do raciocínio de fundamentação desenvolvido, de modo que é possível deduzi-la a partir do argumento de fundamentação de cada voto. Assim, por exemplo, um argumento de ponderação entre direitos fundamentais do feto à vida e da gestante à integridade físico-psíquica e liberdade reprodutiva e sexual pressupõe que se considere que o feto anencefálico está vivo. Caso contrário, não haveria direito à vida (em razão da ausência de vida) que pudesse estar em conflito com os direitos da gestante, tornando a ideia de ponderação sem sentido. 
Interessante é que a discordância sobre o conceito de vida não opõe simplesmente os Ministros que compuseram a maioria e os autores dos dois votos vencidos. A própria maioria vencedora está dividida a este respeito. A situação é tal que alguns Ministros que votaram com a maioria no que se refere à procedência da ação concordam com os autores dos votos vencidos no que se refere ao conceito de vida. Isto pode ser demonstrado com base em três votos exemplares, sintetizados a seguir: o voto do relator, Min. Marco Aurélio; do Min. Cezar Peluso e do Min. Gilmar Mendes ${ }^{18}$.

\subsubsection{VOTO DO MINISTRO MARCO AURÉLIO}

Após traçar os limites da ação, excluindo a discussão geral sobre a criminalização do aborto, e afirmar ser a laicidade do Estado uma premissa da análise da controvérsia sobre a interrupção da gravidez de fetos anencefálicos, o Min. Marco Aurélio, com base em opiniões médicas, define a anencefalia como uma malformação congênita letal ${ }^{19}$.

Aponta que, em termos médicos, há dois processos que indicam a morte: a parada completa e irreversível das funções encefálicas e a parada irreversível das funções cardiorrespiratórias ${ }^{20}$. Segundo o Min. Marco Aurélio, o anencéfalo é como o morto cerebral, pois, como este, carece de atividade cortical ${ }^{21}$. Para fundamentar sua comparação, cita a Res. 1752/2004 do Conselho Federal de Medicina, a qual considera os anencéfalos natimortos cerebrais ${ }^{22}$.

Diante disso, o Ministro conclui que, em casos de anencefalia fetal, não há vida em potencial, mas:

(...) um conflito apenas aparente entre direitos fundamentais. Em rigor, no outro lado da balança, em contraposição aos direitos da mulher,

18 É importante esclarecer que o objetivo desta seção não é criticar os votos dos Ministros do ponto de vista jurídico-dogmático. Em conformidade com o objetivo do artigo, busca-se exclusivamente expor a existência de divergência entre os Ministros no que se refere à vida do feto anencefálico, mostrando como a adoção de cada uma das posições não determina, necessariamente, o voto final de cada Ministro com relação à licitude/ilicitude da interrupção de gravidez. Para uma análise jurídico-dogmática do conceito de vida no acórdão da ADPF n. 54, cf., por todos, SARLET, Ingo Wolfgang. O Supremo Tribunal Federal e o Direito à Vida. Comentários à Decisão na ADPF n. 54 sobre a Interrupção da Gravidez nos Casos de Anencefalia Fetal. Direito. UnB, Brasília, v. 01, n. 02, julho-dezembro de 2014, p. 184-201.

19 BRASIL. STF (Plenário). ADPF n. 54, p. 45.

20 BRASIL. STF (Plenário). ADPF n. 54, p.46.

21 BRASIL. STF (Plenário). ADPF n. 54, p. 44.

22 BRASIL. STF (Plenário). ADPF n. 54, p. 46. 
não se encontra o direito à vida ou à dignidade humana de quem está por vir, justamente porque não há ninguém por vir, não há viabilidade de vida ${ }^{23}$.

Este é seu argumento central, o qual reforça ao tomar posição pela possibilidade de certeza no diagnóstico da anencefalia, mais uma vez, com base em opiniões médicas ${ }^{24}$. O Ministro apresenta ainda um argumento secundário e a refutação de dois possíveis argumentos contrários à sua posição, bem como uma ponderação de (supostos) direitos do feto anencéfalo e da mãe, feita apenas a título argumentativo. O argumento secundário é que o legislador do Código Penal, apesar da visão machista reinante à época, "estabeleceu como impunível o aborto provocado em gestação oriunda de estupro, quando o feto é plenamente viável ${ }^{25}$. Portanto, pode-se concluir, não faz sentido supor que o legislador faria prevalecer supostos direitos do feto sobre os direitos da mulher no caso em que aquele é inviável.

Em resposta à possível objeção de que o legislador deveria (ou poderia) ter previsto a atipicidade da interrupção de gravidez de feto anencefálico expressamente, o Ministro defende que a falta de recursos da medicina para identificar previamente a anencefalia na época da redação do Código Penal explicaria a ausência de dispositivo expresso ${ }^{26}$. A refutação de possível argumento em favor da manutenção da gravidez mesmo diante da ausência de vida do anencéfalo refere-se à ideia de que a gravidez deveria ser mantida para doação de órgãos do bebê.

O Min. Marco Aurélio oferece duas razões para refutar tal argumento, uma principal (capaz de, por si só, refutar a justificativa da doação de órgãos) e uma secundária. A razão principal é que obrigar a manutenção da gravidez para doação de órgãos seria "coisificar a mulher e ferir, a não mais poder a sua dignidade"27.

23 BRASIL. STF (Plenário). ADPF n. 54, p. 54. O uso do termo viabilidade pode causar confusão, mas a analogia com o natimorto cerebral permite concluir, com segurança, que o Ministro não funda sua posição na expectativa de curta duração da vida da criança, mas no fato de que a partir do momento do diagnóstico médico já se sabe que o feto - por ser anencefálico - nascerá morto (com morte cerebral). O que é inviável, portanto, é o nascimento com vida, fato jurídico relevante para a aquisição de capacidade de direito e para justificar a proteção ao nascituro (Código Civil, art. $2^{\circ}$.).

24 BRASIL. STF (Plenário). ADPF n. 54, p. 48; 50; 51

25 BRASIL. STF (Plenário). ADPF n. 54, p. 56.

26 BRASIL. STF (Plenário). ADPF n. 54, p. 56.

27 BRASIL. STF (Plenário). ADPF n. 54, p. 52. 
Neste passo, cita Kant e afirma que não seria possível obrigar a mulher a levar a gestação a termo ainda que os órgãos de anencéfalos fossem necessários para salvar vidas alheias. Lembra, ainda, que no Brasil a doação, mesmo de tecidos como sangue e medula óssea, é voluntária ${ }^{28}$. A razão secundária é que - segundo especialistas médicos - o aproveitamento de órgãos de anencéfalos é praticamente impossível, uma vez que normalmente tais fetos são portadores de diversas outras anomalias e que seus órgãos são menores do que os de bebês saudáveis ${ }^{29}$. Finalmente, apenas a título argumentativo e deixando absolutamente claro não ser esta a sua posição, o Min. Marco Aurélio pressupõe a aceitação do direito à vida do anencéfalo e faz sua ponderação em relação aos direitos da mãe, para concluir que, ainda assim, prevaleceriam os direitos da mulher à dignidade humana, à liberdade sexual, à autonomia, à privacidade, à integridade física, psicológica e moral, bem como à saúde ${ }^{30}$.

\subsubsection{VOTO DO MINISTRO CEZAR PELUSO}

O conceito de vida é pressuposto dos argumentos centrais da decisão do Min. Peluso, os quais consistem na negativa de criação de uma nova causa de exclusão de ilicitude ou de punibilidade não prevista expressamente pelo legislador e em um confronto entre os direitos do feto e da mãe, com prevalência do direito à vida do feto.

O Ministro faz referência a seu próprio voto na ADI n. 3510 (sobre célulastronco embrionárias), em esforço declarado de manter coerência entre suas decisões nos dois casos e conceitua vida como um processo, isto é, como a "(...) sucessão unitária e permanente de mudanças ou contínuo processar-se, que distingue dos entes inanimados os chamados seres vivos"31.

Uma vez que todos os anencéfalos têm tal capacidade de "movimento autógeno", o Ministro conclui que estão vivos ${ }^{32}$.

28 BRASIL. STF (Plenário). ADPF n. 54, p. 53.

29 BRASIL. STF (Plenário). ADPF n. 54, p. 52-54.

30 BRASIL. STF (Plenário). ADPF n. 54, p. 69.

31 BRASIL. STF (Plenário). ADPF n. 54, p. 377. Como se verá, o esforço do Ministro Peluso não é capaz de garantir a coerência das decisões do Tribunal em si, mas apenas de seus próprios votos. 
O Ministro responde, em seguida, ao argumento de que os anencéfalos seriam "mortos cerebrais", afirmando que é errado pretender estabelecer o conceito de vida contrario sensu a partir do conceito de morte encefálica ${ }^{33}$. Peluso elenca cinco razões por que não se pode aplicar a ideia de morte encefálica aos anencéfalos:

A morte encefálica seria uma situação de prognóstico de irreversibilidade, o qual inclui a impossibilidade de respiração espontânea. Tal prognóstico não se aplica aos anencéfalos, os quais podem vir a respirar espontaneamente ${ }^{34}$;

Não há consenso entre os especialistas sobre a existência de atividade e ondas cerebrais no anencéfalo (como teria ficado claro na audiência pública) ${ }^{35}$;

$O$ anencéfalo tem parte do encéfalo ${ }^{36}$;

"A morte encefálica (...) representa interrupção definitiva e irreversível do ciclo vital (...); já a anencefalia integra, ainda que brevemente, o processo contínuo e progressivo a que chamamos vida" (grifos no original) ${ }^{37}$;

“(...) a definição legal de morte encefálica é só operacional, enquanto dirigida, pragmaticamente, a garantir aproveitabilidade de órgãos para fins imediatos de transplante. Não é, pois, conceito normativo suscetível de aplicação a qualquer situação factual (...)"38. Em outras palavras, para o Min. Peluso (ao contrário do Min. Marco Aurélio), a noção de morte encefálica da lei de transplantes não corresponde a um conceito geral de morte - do qual se poderia deduzir contrario sensu -, o conceito de vida, mas uma exceção aplicável apenas à situação de transplantes de órgãos.

Estabelecido o pressuposto de que o feto anencéfalo está vivo no útero materno, o Min. Peluso conclui pela ilicitude da interrupção da gravidez com base em dois argumentos principais: a ausência da necessária causa de exclusão de ilicitude ou punibilidade legal e a prevalência do direito à vida sobre os demais direitos fundamentais. 
Começa notando que o Direito Penal brasileiro proíbe a interrupção de gravidez de feto vivo ao criminalizar o aborto, proibição esta que não pressupõe potencialidade de vida fora do útero materno ${ }^{39}$. De modo que a única possibilidade de que a interrupção de gravidez de feto anencefálico não caracterizasse crime seria -"quando muito", reforça o Min. Peluso - que o legislador tivesse previsto uma excludente de ilicitude ou de punibilidade específica para este caso, o que não foi feito. Segundo o Ministro, a "Corte não tem competência para abolir ou atenuar" crime tipificado em lei ${ }^{40}$. O Ministro nega igualmente a possibilidade de prevalência de direitos da mãe, como saúde psíquica e liberdade pessoal, sobre o direito à vida do feto anencéfalo ${ }^{41}$.

Segundo o Min. Peluso, os direitos sexuais e reprodutivos da mulher, entendidos como "derivações práticas da extensão da liberdade pessoal da mulher" são estritos e não permitem "o reconhecimento da existência de poder absoluto de eliminar a vida intrauterina". Tal poder implicaria "a completa reificação do concepto, transformado em mero objeto disponível, sem nenhuma dignidade jurídica"42. Citando sua própria decisão na ADI n. 3510, o Min. Peluso deixa clara sua posição a favor da prevalência do direito à vida, em caso de conflito com outros direitos fundamentais, ao afirmar que o direito à vida é "o pressuposto ou condição transcendental da existência de todos os direitos subjetivos"43 (grifo no original. Sua posição está bem sintetizada no trecho a seguir:

A vida humana, imantada de dignidade intrínseca, anterior ao próprio ordenamento jurídico, não pode ser relativizada fora das específicas hipóteses legais (...) Havendo vida, e vida humana - atributo de que é dotado o feto ou bebê anencéfalo -, está-se diante de valor jurídico fundante e inegociável, que não comporta, nessa estima, margem alguma para transigência. Cuida-se como já afirmei, "do valor mais importante do ordenamento jurídico". ${ }^{44}$ (grifos no original)

O Ministro ainda responde ao possível argumento de que obrigar a mulher a manter a gravidez de feto anencefálico equivaleria à tortura, afirmando que neste caso faltam os elementos da injustiça e do caráter intencional do 


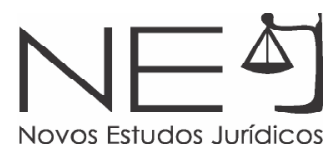

sofrimento imposto, que, além do mais, deveria ser passível de ser evitado de modo compatível com o ordenamento jurídico para que o argumento pudesse ser aceito ${ }^{45}$. Finalmente, como argumento secundário, o Min. Peluso aponta a grande dificuldade técnica de se estabelecer com precisão absoluta o diagnóstico de anencefalia ${ }^{46}$.

\subsubsection{VOTO DO MINISTRO GILMAR MENDES}

No voto do Min. Gilmar Mendes não há muita discussão direta sobre o conceito de vida, mas lá se distingue expressamente anencefalia de morte cerebral. Fundamento para a distinção é, segundo o Min. Gilmar Mendes, o fato de que o anencéfalo é capaz de respiração autônoma, ao contrário do morto cerebral, que necessita de aparelhos ${ }^{47}$. De todo modo, o argumento do Ministro pressupõe que o feto anencéfalo esteja vivo no útero materno, uma vez que trata de fundamentar uma excludente de ilicitude não expressa no CP em relação ao crime de aborto.

A partir do fato de que o legislador penal previu situações de aborto permitido para proteger a saúde física e psíquica da gestante, constatando que a gravidez de feto anencéfalo traz riscos físicos e psíquicos aumentados à gestante e que, em 1940, não havia tecnologia médica capaz de permitir o diagnóstico de anencefalia, o Min. Gilmar Mendes faz "interpretação evolutiva" do CP, para adaptá-lo ao novo contexto fático-jurídico, admitindo a anencefalia como terceira causa de exclusão de ilicitude (não expressa) em caso de aborto ${ }^{48}$.

O Ministro chama atenção ainda para o fato de que, se os danos psíquicos derivados da gestação de feto anencefálico não podem ser considerados tão graves quanto aqueles decorrentes de uma gravidez resultante de estupro, é preciso levar em conta que, no caso de estupro, o legislador permite a interrupção de gravidez de um feto perfeitamente saudável, ao passo que, no caso de anencefalia, além do dano psíquico à gestante, há o fato da "inviabilidade quase certa de vida extrauterina do feto" 49 . 
Com base nesses argumentos, o Min. Gilmar Mendes conclui que a interrupção de gravidez quando o feto é anencefálico está compreendida entre as duas causas de exclusão de ilicitude já expressamente previstas no Código Penal. O avanço das possibilidades de diagnóstico de anencefalia fetal fez com que a não inclusão desta causa excludente de ilicitude passasse a constituir uma omissão legislativa incompatível tanto com o próprio Código Penal, quanto com a Constituição Federal ${ }^{50}$.

\section{DECISÃO POR MAIORIA E RACIONALIDADE COLETIVA}

A comparação entre os votos exemplares sintetizados anteriormente mostra que é possível divergir não apenas quanto ao deferimento ou ao indeferimento do pedido, mas também sobre os fundamentos desta decisão. O Min. Gilmar Mendes concorda com o Min. Marco Aurélio em relação ao pedido, mas não em relação ao fundamento; e concorda com o Min. Cezar Peluso no que se refere ao fundamento em questão (vida do feto), mas não quanto ao pedido. Enquanto o Min. Marco Aurélio considerou o feto anencéfalo como morto; os Mins. Gilmar Mendes e Cezar Peluso o consideraram como vivo.

Diante disso, que sentido se pode atribuir à decisão do STF neste caso? Sem dúvida, é possível concluir a partir da decisão da ADPF n. 54, que a interrupção de gravidez de feto anencefálico não é crime no Brasil. Esta questão está encerrada. Mas será possível afirmar algo sobre o que constitui "vida" para o tribunal?

Não parece possível afirmar que exista uma posição do STF a respeito desta questão na decisão da ADPF n. 54. E isto apesar de todos os Ministros que participaram do julgamento terem assumido uma posição individual a este respeito em seus votos. O que se tem são posições individuais acerca do conceito de vida. A decisão final com relação a este ponto não tem nenhum fundamento racional coletivo e, portanto, não consagra nenhuma posição do tribunal a respeito do que seja vida ou morte no direito brasileiro, capaz de vincular possíveis decisões futuras acerca de casos considerados semelhantes. 
A razão para isto é que, como demonstram List e Pettit ${ }^{51}$, é impossível derivar racionalidade coletiva diretamente da racionalidade individual. Pelo contrário, para que um ente colegiado seja capaz de constituir um agente racional, é preciso que se quebre a relação direta entre os juízos individuais e os juízos coletivos ${ }^{52}$. Mais especificamente, o que esses autores afirmam é que nenhum procedimento de agregação de decisões individuais que, como é o caso da votação por maioria, apresente simultaneamente as características de domínio universal, anonimato e sistematicidade, é capaz de garantir que a decisão coletiva seja racional. Trata-se de uma impossibilidade lógica ${ }^{53}$.

A característica de domínio universal significa que o procedimento de agregação em questão aceita como input qualquer conjunto de juízos individuais logicamente possível, desde que satisfeitos os requisitos de completude, consistência e fechamento dedutivo. Um conjunto de juízos será completo se contiver uma afirmação ou negação de cada uma das questões que precisa ser decidida. Será consistente se não contiver simultaneamente uma afirmação e sua negação. E será fechado dedutivamente se todas as proposições que resultem logicamente das afirmações que o conjunto contém também estejam contidas nele ${ }^{54}$. Como se percebe, essas exigências implicam apenas que as decisões individuais sejam de fato tomadas e não sejam em si mesmas contraditórias, requisitos mínimos para que possam ser consideradas individualmente racionais. De modo que o requisito do domínio universal significa que quaisquer juízos individuais são aceitos no procedimento de agregação, desde que sejam racionais.

A característica de domínio universal está presente no modo de decisão do STF, uma vez que este não exclui a priori nenhuma posição logicamente possível e é razoável supor que os votos individuais cumpram requisitos básicos de racionalidade.

$51 \quad$ LIST, Christian e PETTIT, Philip. Aggregating Sets of Judgments: an Impossibility Result, p. 98-99. Kornhauser e Sager já haviam identificado o problema da falta de relação imediata entre racionalidade individual e coletiva, embora sem dar ao problema o tratamento sistemático dado por List e Pettit. Cf. KORNHAUSER, Lewis A. e SAGER, Lawrence G. The One and the Many: Adjudication in Collegial Courts. California Law Review, Berkeley, V. 81, n. 1, p. 11.

52 LIST, Christian e PETTIT, Philip. Aggregating Sets of Judgments: an Impossibility Result, p. 98. Trata-se do que os autores chamam de "dilema discursivo": os indivíduos precisam optar entre um método de agregação de juízos que corresponda aos juízos individuais e à racionalidade coletiva.

53 Cuja demonstração formal pode ser encontrada em LIST, Christian e PETTIT, Philip. Aggregating Sets of Judgments: an Impossibility Result, p. 108-110.

54 LIST, Christian e PETTIT, Philip. Aggregating Sets of Judgments: an Impossibility Result, p. 97. 
A característica de anonimato, por sua vez, significa que o procedimento de agregação não distingue entre os juízos dos membros do grupo, tendo, todos, o mesmo peso. É o que ocorre no STF, em que cada Ministro tem um voto e todos os votos têm o mesmo valor. Finalmente, a característica da sistematicidade implica que o processo de agregação é o mesmo para todas as proposições, de modo que o juízo coletivo é formado apenas pelos juízos individuais sobre cada proposição, independentemente de qual seja a proposição em questão.

Esta característica está igualmente presente no procedimento do STF para as decisões coletivas, uma vez que não há votação acerca das premissas, com o resultado do julgamento sendo a decorrência lógica das decisões majoritárias acerca destas. O que se verifica é que cada Ministro decide de forma autônoma sobre todas as questões envolvidas no caso, isto é, tanto sobre as premissas quanto sobre a conclusão. Disso resulta que, sendo a decisão coletiva formada diretamente pela agregação das decisões individuais, em um procedimento de decisão por maioria, como o do STF, a racionalidade permanece individual e será refletida coletivamente apenas por acaso ${ }^{55}$.

Evidentemente, sendo a coletividade formada por indivíduos, são os juízos individuais que determinam os juízos coletivos. Afirmar que a racionalidade coletiva não pode ser derivada da racionalidade individual não significa, portanto, que inexista relação entre ambas, mas apenas que tal relação não é causal, mas uma relação de superveniência holística ${ }^{56}$.

55 A boa deliberação interna constitui um fator de qualidade das decisões colegiadas nos tribunais e é certo que o momento de produção da decisão escrita deve configurar, como afirma Hübner Mendes, um "esforço de tradução da deliberação colegiada numa decisão supraindividual, que não se confunde com mera soma de opiniões isoladas (...)" Cf. HÜBNER MENDES, Conrado. Desempenho deliberativo de cortes constitucionais e o STF. In: MACEDO Jr., Ronaldo Porto e BARBIERI, Catarina Helena Cortada (Orgs.). Direito e Interpretação. Racionalidade e Instituições. São Paulo: Saraiva, 2011, p. 352-353. No entanto, é preciso distinguir os problemas. O que se afirma aqui é que, mesmo sendo uma característica institucional positiva, a boa deliberação interna não é capaz de garantir a produção de decisões racionalmente fundamentadas na dimensão coletiva, quando o sistema de agregação de posições individuais tem as características de domínio universal, anonimato e sistematicidade. A deliberação poderia, em tese, ser um instrumento de relaxamento da característica de domínio universal. Neste caso, os ministros deveriam deliberar até que suas posições convergissem ao ponto de constituir uma decisão racional do ponto de vista coletivo. Embora seja possível do ponto de vista lógico, esta solução não seria realizável na prática, tendo em vista a impossibilidade de adiar indefinidamente a decisão ou de deixar de decidir por falta de acordo. Cf. neste sentido: LIST, Christian e PETTIT, Philip. Group Agency. The Possibility, Design, and Status of Corporate Agents. Oxford: Oxford University Press, 2011, p. 52.

56 LIST, Christian e PETTIT, Philip. Group Agency. The Possibility, Design, and Status of Corporate Agents, $p$. 65-67. 
A superveniência é um conceito que explica a relação de determinação entre fenômenos de níveis diferentes: um padrão do fenômeno no "nível inferior" determina o padrão do fenômeno no "nível superior", mas deixa aberta a possibilidade de que o padrão no "nível superior" possa ser constituída a partir de vários padrões no "nível inferior"57.

No caso de colegiados que decidem questões interligadas do ponto de vista lógico e são capazes de decisões racionais no plano coletivo, a relação de superveniência se estabelece não com base no conjunto das posições individuais em relação a cada uma das proposições na agenda, mas no conjunto das posições individuais acerca do conjunto das proposições na agenda, sendo por isso uma relação de superveniência holística ${ }^{58}$.

A racionalidade coletiva é possível, portanto, mas não por meio do procedimento de agregação de juízos individuais empregado pelo STF. Para obtê-la, seria necessário abrir mão de pelo menos uma das três características do procedimento de simples agregação de juízos individuais mencionadas anteriormente: domínio universal, anonimato ou sistematicidade ${ }^{59}$.

Não será feita aqui uma análise das vantagens e das desvantagens de cada uma dessas possibilidades e dos procedimentos decisórios daí resultantes, pois o objetivo deste trabalho não é sugerir alterações no procedimento decisório do STF. O que interessa é encarar o fato de que cada acórdão do STF consiste em um conjunto de decisões racionais individuais e não em uma decisão coletiva com racionalidade coletiva.

Tendo em vista que o procedimento de votação por maioria agrega apenas o resultado dessas decisões individuais - e não seu fundamento -, note-se que é possível até mesmo haver uma decisão final na ação que não corresponda à opinião da maioria com relação aos fundamentos.

57 Exemplos de relações de superveniência são aquelas existentes entre as capacidades mentais de uma pessoa e suas características biológicas e entre características culturais e as disposições individuais dos membros de dada cultura (cf. LIST, Christian e PETTIT, Philip. Group Agency. The Possibility, Design, and Status of Corporate Agents, p. 65).

58 Isto explica por que a decisão coletiva, embora determinada pelas posições individuais, pode divergir da posição dos indivíduos em relação a cada um dos pressupostos lógicos da decisão, como se verá no exemplo a seguir. LIST, Christian e PETTIT, Philip. Group Agency. The Possibility, Design, and Status of Corporate Agents, p. 69. 
Isto pode ser demonstrado com um exemplo simples, extraído também da obra de List e Pettit ${ }^{60}$. Imaginar-se-á que três indivíduos $(A, B$ e $C)$, os quais são simultaneamente funcionários e titulares de uma empresa, precisam decidir se concedem a si mesmos um aumento de salário ou usam a verba disponível para aumentar a segurança no local de trabalho, por meio da instalação de um dispositivo contra choques elétricos.

Todos eles concordam que esta decisão depende da decisão sobre três outras questões que lhe são prévias. Será preciso decidir primeiro:

se existe realmente um risco grande de eletrocussão;

se o dispositivo de segurança é realmente eficaz para evitar o risco de eletrocussão;

se o sacrifício financeiro implicado pode ser razoavelmente suportado por todos os indivíduos envolvidos.

Como os indivíduos do exemplo são todos racionais, qualquer um deles que responder a essas três questões afirmativamente votará pela instalação do dispositivo de segurança. Ao contrário, os indivíduos que responderem negativamente a qualquer uma delas votarão pelo aumento de salário. Irá se supor que, depois de deliberarem, os indivíduos façam uma votação e seus votos sejam os seguintes:

\begin{tabular}{|l|l|l|l|l|}
\hline & Perigo grave? & Medida eficaz? & Sacrifício suportável? & Instalação do dispositivo? \\
\hline$A$ & SIM & NÃO & SIM & NÃO \\
\hline$B$ & NÃO & SIM & SIM & NÃO \\
\hline$C$ & SIM & SIM & NÃO & NÃO \\
\hline
\end{tabular}

Note-se que, embora todos os indivíduos tenham decidido racionalmente, a decisão final coletiva é irracional, pois não reflete o juízo coletivo em relação às premissas para a decisão final. Para cada uma das premissas há uma maioria de votos positivos, de modo que a consequência racional seria uma decisão positiva também com relação à questão da instalação do dispositivo de segurança.

60 LIST, Christian e PETTIT, Philip. Aggregating Sets of Judgments: an Impossibility Result, p. 108-109. 
O exemplo mostra que, como se disse, a simples agregação de decisões individuais racionais não garante decisões coletivas racionais e pode até mesmo levar a resultado contrário à posição da maioria dos indivíduos em relação às premissas para a decisão.

No caso da ADPF n. 54, não se chegou à situação na qual a maioria com relação à procedência do pedido contradiz a maioria com relação aos fundamentos (embora isto possa, em tese, acontecer em decisões do STF). Para o que interessa aos objetivos deste texto, importa notar que, em virtude da falta de uma racionalidade propriamente coletiva, existe uma decisão coletiva sobre a procedência do pedido, mas não sobre o conceito de vida, um de seus fundamentos. Senão veja-se.

Comparando a posição dos Ministros com relação à procedência da ação, tem-se o seguinte resultado ${ }^{61}$ :

\begin{tabular}{|l|l|l|}
\hline MINISTRO & PROCEDENTE & IMPROCEDENTE \\
\hline Marco Aurélio & $\mathrm{X}$ & \\
\hline Rosa Weber & $\mathrm{X}$ & \\
\hline Joaquim Barbosa & $\mathrm{X}$ & \\
\hline Luiz Fux & $\mathrm{X}$ & \\
\hline Carmen Lúcia & $\mathrm{X}$ & \\
\hline Ricardo Lewandowski & & $\mathrm{X}$ \\
\hline Ayres Britto & $\mathrm{X}$ & \\
\hline Gilmar Mendes & $\mathrm{X}$ & \\
\hline Celso de Mello & $\mathrm{X}$ & \\
\hline Cezar Peluso & & $\mathrm{X}$ \\
\hline Dias Toffoli & impedido & $\mathbf{2}$ \\
\hline TOTAL & $\mathbf{8}$ & \\
\hline
\end{tabular}

61 A rigor, os Ministros Gilmar Mendes e Celso de Mello julgaram a ação procedente, mas estabeleceram condições para o diagnóstico da anencefalia. Esta específica divisão na maioria, no entanto, não interessa aqui, pois não se relaciona com a concepção de vida defendida pelos Ministros, mas apenas com a discussão secundária a respeito da possibilidade de certeza de diagnóstico. 
Já a comparação das posições dos Ministros com relação a estar o feto anencéfalo vivo ou morto há resultado bastante diferente ${ }^{62}$.

\begin{tabular}{|l|l|l|}
\hline MINISTRO & VIVO & MORTO \\
\hline Marco Aurélio & & X \\
\hline Rosa Weber & & X \\
\hline Joaquim Barbosa & X & \\
\hline Luiz Fux & X & \\
\hline Carmen Lúcia & & X \\
\hline Ricardo Lewandowski & X & \\
\hline Ayres Britto & & X \\
\hline Gilmar Mendes & X & \\
\hline Celso de Mello & & X \\
\hline Cezar Peluso & X & \\
\hline Dias Toffoli & impedido & \\
\hline TOTAL & $\mathbf{5}$ & $\mathbf{5}$ \\
\hline
\end{tabular}

Diante disso, como afirmar que uma próxima decisão, a qual também dependa do conceito de vida, é coerente com a decisão da ADPF n. 54?

Evidentemente que não se supõe que de uma decisão sobre o conceito de vida pudesse ser simplesmente deduzida a posição do STF em relação a outros problemas que envolvessem esse conceito, afinal, como afirma MacCORMICK ${ }^{63}$, argumentos jurídicos não são racionalmente demonstrativos, mas racionalmente persuasivos. Isso significa que argumentos jurídicos podem ser avaliados e criticados, mas sua correção não tem como ser demonstrada logicamente. De modo que sempre haveria espaço para que o tribunal, em casos futuros, fizesse distinções do novo caso em relação ao problema da interrupção de gravidez de feto anencefálico.

62 Naturalmente, a referência a um placar de votação com relação ao pressuposto é figurada. Os Ministros votam apenas com relação ao deferimento ou ao indeferimento do pedido. Marta Rodriguez de Assis Machado e Rebecca J. Cook fazem referência à existência de seis votos que consideram o feto anencefálico como vivo. As autoras não citam, porém, os autores de tais votos, o que impossibilita a identificação da razão da divergência entre seu entendimento e o apresentado aqui (cf. MACHADO, Marta Rodriguez de Assis e COOK, Rebecca J. Constitutionalizing Abortion in Brazil. Revista de Investigações Constitucionais, Curitiba, v. 5, n. 3, p. 205, setembro/dezembro de 2018).

63 MacCORMICK, Neil. Rhetoric and the Rule of Law: A Theory of Legal Reasoning. Oxford: Oxford University Press, 2005, p. 279. 
O que se quer dizer, portanto, não é que a decisão da ADPF n. 54, caso fosse racional na dimensão coletiva, encerraria necessariamente de modo definitivo o debate sobre o sentido jurídico de vida ou morte. A questão é que o fato de não haver racionalidade coletiva impede que se use a decisão como precedente para vincular decisão futura sem - pelo menos - análise dos vários fundamentos apresentados nos votos individuais.

É necessário desenvolver uma teoria do precedente, que permita identificar nos votos aquilo que os justifica, isto é, a regra (ou regras) de precedente propriamente dita (ratio decidendi) e distingui-la de outros aspectos das decisões, aos quais não se atribui o caráter de precedente (obiter dicta) ${ }^{64}$. O caso da ADPF n. 54 deixa claro que as decisões colegiadas do STF podem ter várias justificativas, isto é, várias rationes decidendi, potencialmente incompatíveis entre si.

Quanto mais vinculantes se consideram os precedentes, mais problemática é esta situação. Em alguns casos pode ser possível construir uma regra de precedente que junte as razões de decidir de todos os juízes de um tribunal, mas isso tende a ser raro. Na maior parte das vezes, haverá, senão rationes incompatíveis, pelo menos várias rationes concorrentes ${ }^{65}$. Levando-se em conta este quadro, dizer que as decisões do STF são estritamente vinculantes é dizer quase nada. O resultado da falta de racionalidade coletiva é, portanto, dificultar o estabelecimento de uma regra de precedente e, desse modo, dificultar a adoção de um sistema de precedentes estritamente vinculantes. Isto é o que conecta a discussão feita neste trabalho com o debate doutrinário referido anteriormente, acerca do grau de obrigatoriedade dos precedentes no sistema do CPC.

É por isso que, para MacCORMICK ${ }^{66}$, a reflexão sobre o modelo em que múltiplos juízes apresentam fundamentos individuais para a mesma decisão aponta ser mais adequada a adoção de precedentes com força apenas persuasiva - e não vinculante - sobre decisões futuras.

64 MacCORMICK, Neil. Rhetoric and the Rule of Law: A Theory of Legal Reasoning, p. 146.

65 MacCORMICK, Neil. Rhetoric and the Rule of Law: A Theory of Legal Reasoning, p. 153-154.

66 MacCORMICK, Neil. Rhetoric and the Rule of Law: A Theory of Legal Reasoning, p. 154. Em suas palavras, nessas situações, "devemos reconhecer a imprudência de qualquer doutrina que considere [as rationes decidendi] vinculantes com base em um único caso" (tradução nossa). 


\section{APLICAÇÃO DE PRECEDENTE NO RESP N. 1467888}

Na análise anterior, tratou-se de um aspecto do argumento de fundamentação dos votos dos Ministros do STF: a posição de cada um a respeito da vida do feto anencefálico. O objetivo foi demonstrar a existência de diferentes fundamentos no mesmo acórdão, inclusive para decisões no mesmo sentido, exemplificando a impossibilidade de se derivar diretamente da racionalidade individual a racionalidade coletiva. Passa-se agora à questão do uso de tal decisão como precedente, com base no acórdão no REsp n. 1467888, o qual exemplifica o problema de aplicação de precedente sem atenção à questão da ausência de racionalidade coletiva das decisões do STF.

Em setembro de 2005, uma gestante recebeu a notícia de que seu feto fora diagnosticado como portador da síndrome de body stalk, uma rara anomalia congênita cuja principal característica é um grave defeito na parede abdominal, a qual não se fecha. Isso significa que os órgãos internos do feto se encontram expostos, fora da cavidade abdominal, com a consequente inviabilidade de vida extrauterina. Diante disso, a gestante pediu autorização judicial para interromper a gravidez, a qual foi concedida em 06 de outubro do mesmo ano ${ }^{67}$.

O processo de indução do parto, iniciado em 11 de outubro, foi interrompido dois dias depois, em razão do deferimento de medida liminar em habeas corpus impetrado por um padre em favor do feto ${ }^{68}$. A gestante recebeu alta. No dia 22 de outubro, ela retornou ao hospital em trabalho de parto e deu à luz uma criança com síndrome de body stalk, que faleceu uma hora e quarenta minutos após o nascimento ${ }^{69}$.

A mulher e seu marido, então, propuseram ação de responsabilidade civil por danos morais contra o padre que havia impetrado o habeas corpus.

67 BRASIL. Superior Tribunal de Justiça (3a. Turma). Controvérsia: dizer se o manejo de habeas corpus, pelo recorrido, com o fito de impedir a interrupção da gestação da primeira recorrente, que tinha sido judicialmente deferida, caracteriza-se como abuso do direito de ação e/ou ação passível de gerar responsabilidade civil de sua parte, pelo manejo indevido de tutela de urgência (...) Recurso especial conhecido e provido. Recurso Especial n. 1467888. Relatora: Ministra Nancy Andrighi. J. em 20/10/2016, p. 7 e 11. Disponível em: <https://ww2.sti.jus. $\mathrm{br} / \mathrm{processo} / \mathrm{revista} /$ documento/mediado/?componente=|TA\&sequencial $=1548482 \&$ num_registro $=201401589820$ \&data=20161025\&formato=PDF >. Acesso em: 28 de maio de 2018.

68 BRASIL. Superior Tribunal de Justiça (3a. Turma). Recurso Especial n. 1467888, p. 5 e 8.

69 BRASIL. Superior Tribunal de Justiça (3a. Turma). Recurso Especial n. 1467888, p. 8. 
A sentença julgou improcedente o pedido. Foi negado provimento ao agravo regimental interposto, bem como rejeitados os embargos de declaração. Diante disso, o casal interpôs recurso especial ${ }^{70}$.

Em 20 de outubro de 2016, a Terceira Turma, por unanimidade e nos termos do voto da relatora, Min. Nancy Andrighi, condenou o padre a indenizar o casal por danos morais no valor de sessenta mil reais ${ }^{71}$. Central para a solução da controvérsia era a questão sobre a ilicitude da conduta do recorrido, isto é, da impetração de habeas corpus para impedir a interrupção da gravidez de feto portador de síndrome de body stalk, autorizada pela Justiça.

Em seu voto, a Min. Nancy Andrighi estabelece a ilicitude da conduta a partir da aplicação da decisão da ADPF n. 54 como precedente. Como afirma a ministra, "onde existe a mesma razão, deve haver a mesma regra de Direito"72. Dedica-se, portanto, em seu voto, a "perquirir os porquês da decisão tomada pelo STF, tendo em vista que elas dirão se as hipóteses (anencefalia e síndrome de body stalk) são símeis e, por conseguinte, dão azo à mesma interpretação constitucional"73.

No entanto, para estabelecer os fundamentos da decisão do STF, a Ministra usa exclusivamente o voto do Relator, Min. Marco Aurélio, o qual, como se viu, não reflete a variedade de fundamentos adotados pelos ministros que compuseram a maioria naquele caso.

Além disso, é duvidoso que a própria posição do Min. Marco Aurélio seja capaz de embasar a analogia que a Min. Nancy Andrighi faz entre a anencefalia e a síndrome de body stalk. De acordo com a interpretação da ministra, embora o direito proteja o nascituro:

No julgamento da ADPF 54, (...) viu-se que esse tegumento protetivolegal que envolve o nascituro, torna-se completamente inócuo ante a constatação de que o feto é portador de problemas de saúde, de qualquer matriz, que tornam inviável a vida extrauterina, isso porque, a proteção que se projeta para o futuro, labora com realidade inexistente: vida extrauterina ${ }^{74}$ (grifos nossos).

70 BRASIL. Superior Tribunal de Justiça (3a. Turma). Recurso Especial n. 1467888, p. 4-5

71 BRASIL. Superior Tribunal de Justiça ( ${ }^{\text {a }}$. Turma). Recurso Especial n. 1467888, p. 25-27.

72 BRASIL. Superior Tribunal de Justiça (3a. Turma). Recurso Especial n. 1467888, p. 16.

73 BRASIL. Superior Tribunal de Justiça (3a. Turma). Recurso Especial n. 1467888, p. 13.

74 BRASIL. Superior Tribunal de Justiça (3a. Turma). Recurso Especial n. 1467888, p. 14 
Completa a Ministra, especificando que:

Quando se fala em inviabilidade de vida extrauterina, não necessariamente se aponta para o fenecimento da vida átimos de segundos após o nascimento, mas sim, da certeza médica de que a condição física do feto não lhe dará oportunidade de ter nenhuma vida pós-parto, sendo questão de tempo, o óbito da criança nascida sob o signo dessa condição, e decorrendo o falecimento das consequências associadas à síndrome ${ }^{75}$.

Segundo a Min. Nancy Andrighi, o STF teria fixado que "o peso específico do direito a uma futura não-vida, não pode preponderar sobre o direito da mulher à liberdade, intimidade e autodeterminação"76.

No entanto, justamente o voto do Relator na ADPF n. 54 não se funda, a rigor, na ponderação dos pesos específicos da vida do feto e dos direitos da mulher. O raciocínio que o Min. Marco Aurélio desenvolve nesse sentido é expressamente ad argumentandum tantum ${ }^{77}$.

\section{CONSIDERAÇÕES FINAIS}

O objetivo deste artigo não foi afirmar a inexistência de regra de precedente na decisão da ADPF n. 54 pelo STF. Tampouco queremos afirmar que, caso uma regra de precedente possa ser extraída do acórdão, esta seja diferente daquela empregada pelo STJ na decisão do REsp. n. 1467888.

Um sistema de agregação de votos por maioria não impede a priori a existência de um sistema de precedentes. No entanto, é preciso levar em conta que tal sistema propõe desafios específicos para o uso de precedentes.

O primeiro e principal deles é que, em virtude da falta de garantia de existência de fundamento racional coletivo, nem toda decisão do STF serve necessariamente como precedente, ainda que a votação seja unânime em relação ao pedido, pois é possível que não exista maioria em relação às razões de decidir.

75 BRASIL. Superior Tribunal de Justiça (3a. Turma). Recurso Especial n. 1467888, p. 13.

76 BRASIL. Superior Tribunal de Justiça (3a. Turma). Recurso Especial n. 1467888, p. 15.

77 BRASIL. Superior Tribunal de Justiça (3a. Turma). Recurso Especial n. 1467888, p. 69. O fundamento da decisão do Min. Marco Aurélio, como se viu anteriormente, é que já se sabe que o feto anencefálico nunca terá atividade encefálica ao nascer, sendo um natimorto cerebral, situação que, evidentemente, não se aplica ao feto com síndrome de body stalk, já que este tem atividade encefálica. 


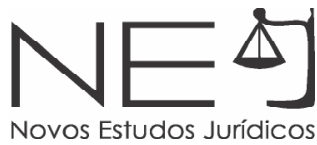

O segundo desafio é o estabelecimento da própria regra de precedente, nos casos em que ela exista. Não será possível fazer isso pela análise dos fundamentos de um único voto ${ }^{78}$. Será necessário analisar um a um os votos dos ministros, em busca de suas rationes decidendi, o que implica adotar alguma concepção não apenas sobre como identificar tais rationes, mas também sobre qual peso dar a rationes diversas e potencialmente incompatíveis.

Sem isso, a exigência do art. 489, § 1., VI do Código de Processo Civil de 2015 torna-se uma autorização para a seleção discricionária de posições individuais em casos já julgados, o que resultaria em uma multiplicação de soluções, conforme cada juiz ou tribunal selecione diferentes posições de um mesmo acórdão para empregar como precedente, frustrando-se o objetivo de obter mais racionalidade, previsibilidade e segurança jurídica nas decisões judiciais.

O modo como o STJ empregou a decisão da ADPF n. 54 para decidir o recurso especial analisado parece indicar que as consequências de um sistema de agregação de votos por maioria não foram reconhecidas.

Um sistema de precedentes vinculantes é algo extremamente complexo e não depende apenas do procedimento de agregação das razões de decidir dos tribunais. No entanto, sem atenção ao modo como está institucionalizada tal agregação no STF, não será possível desenvolver uma teoria do precedente para o direito brasileiro sobre bases adequadas. Corre-se o risco de, na tentativa de unificar a interpretação da Constituição, não apenas aumentar a fragmentação das interpretações, como abrir espaço para a arbitrariedade.

\section{REFERÊNCIAS DAS FONTES CITADAS}

BARROSO, Luis Roberto. Petição inicial na ADPF n. 54. Disponível em: <http://redir.stf.jus. br/estfvisualizadorpub/jsp/consultarprocessoeletronico/ConsultarProcessoEletronico.jsf?seq objetoincidente=2226954 > . Acesso em: 12 de fevereiro de 2014 .

BRASIL. Congresso Nacional. Senado Federal. Comissão de Juristas Responsável pela Elaboração de Anteprojeto de Código de Processo Civil. Código de Processo Civil: anteprojeto. Brasília: Senado Federal, Presidência, 2010.

78 A não ser no caso em que todos os votantes acompanhem o relator sem consignar razões próprias em voto em separado, como foi o caso do REsp n. 1467888. 
BRASIL. STF (Plenário). ESTADO - Laicidade. O Brasil é uma república laica, surgindo absolutamente neutro quanto às religiões. Considerações. Feto anencéfalo - Interrupção da gravidez - Mulher - Liberdade sexual e reprodutiva - Saúde - Dignidade - Autodeterminação - Direitos fundamentais - Crime - Inexistência. Mostra-se inconstitucional interpretação de a interrupção da gravidez de feto anencéfalo ser conduta tipificada nos artigos 124, 126 e 128, incisos I e II, do Código Penal. ADPF n. 54. Relator: Ministro Marco Aurélio. J. em 12/04/2012. Disponível em: <http://redir.stf.jus.br/paginadorpub/paginador .jsp? docTP $=$ TP\&docID=3707334 $>$. Acesso em: 23 de outubro de 2013.

BRASIL. Superior Tribunal de Justiça (3a. Turma). Controvérsia: dizer se o manejo de habeas corpus, pelo recorrido, com ofito de impedir a interrupção da gestação da primeira recorrente, que tinha sido judicialmente deferida, caracteriza-se como abuso do direito de ação e/ou ação passível de gerar responsabilidade civil de sua parte, pelo manejo indevido de tutela de urgência (...) Recurso especial conhecido e provido. Recurso Especial n. 1467888. Relatora: Ministra Nancy Andrighi. J. em 20/10/2016. Disponível em: <https://ww2.stj.jus.br/processo/ revista/documento/mediado/?componente $=$ ITA\&sequencial $=1548482$ \&num_registro $=2014$ $01589820 \&$ data $=20161025 \&$ formato $=$ PDF $>$. Acesso em: 28 de maio de 2018.

BUENO, Cassio Scarpinella. Novo Código de Processo Civil anotado. São Paulo: Saraiva, 2015.

CRUZ E TUCCI, José Rogério. In: BUENO, Cassio (Org.). Comentários ao Código de Processo Civil. Vol. 4. São Paulo: Saraiva, 2017, p. 17-53.

GROSS CUNHA, Luciana e ALMEIDA, Frederico de. Justiça e desenvolvimento econômico na Reforma do Judiciário brasileiro. In: SCHAPIRO, Mario G. e TRUBEK, David M. Direito e Desenvolvimento: Um diálogo entre os BRICS. São Paulo: Saraiva, 2012, p. 361-386.

HÜBNER MENDES, Conrado. Desempenho deliberativo de cortes constitucionais e o STF. In: MACEDO Jr., Ronaldo Porto e BARBIERI, Catarina Helena Cortada (Orgs.). Direito e Interpretação: Racionalidade e Instituições. São Paulo: Saraiva, 2011, p. 337-361.

KORNHAUSER, Lewis A. e SAGER, Lawrence G. The One and the Many: Adjudication in Collegial Courts. California Law Review, Berkeley, v. 81, n. 1, p. 1-59. Janeiro de 1993.

LIST, Christian e PETTIT, Philip. Aggregating Sets of Judgments: an Impossibility Result. In: Economics and Philosophy, Cambridge, v. 18, p. 89-110. 2002.

Group Agency: The Possibility, Design, and Status of Corporate Agents. Oxford: Oxford University Press, 2011.

MacCORMICK, Neil. Rhetoric and the Rule of Law: A Theory of Legal Reasoning. Oxford: Oxford University Press, 2005. 
MACHADO, Marta Rodriguez de Assis e COOK, Rebecca J. Constitutionalizing Abortion in Brazil. Revista de Investigações Constitucionais, Curitiba, v. 5, n. 3, p. 185-231, setembro/ dezembro de 2018.

MANCUSO, Rodolfo de Camargo. O direito brasileiro segue filiado (estritamente) à família Civil Law? In: O Novo Código de Processo Civil: Questões Controvertidas. São Paulo: Atlas, 2015, p. 387-420.

MARINONI, Luiz Guilherme, ARENHART, Sérgio Cruz e MITIDIERO, Daniel. Novo Código de Processo Civil comentado. São Paulo: RT, 2015.

. Novo curso de Processo Civil, vol. 1, 2ª ed. São Paulo: RT, 2016.

NERY Jr., Nelson e NERY, Rosa Maria de Andrade. Comentários ao Código de Processo Civil. São Paulo: RT, 2015.

SARLET, Ingo Wolfgang. O Supremo Tribunal Federal e o Direito à Vida. Comentários à Decisão na ADPF n. 54 sobre a Interrupção da Gravidez nos Casos de Anencefalia Fetal. Direito. UnB, Brasília, v. 01, n. 02, julho-dezembro de 2014, p. 184-201.

THEODORO Jr., Humberto, NUNES, Dierle, BAHIA, Alexandre Melo Franco e PEDRON, Flávio Quinaud. Novo CPC: Fundamentos e sistematização. Rio de Janeiro: Forense, 2016.

WAMBIER, Teresa Arruda Alvim, CONCEIÇÃO, Maria Lúcia Lins, RIBEIRO, Leonardo Ferres da Silva e MELLO, Rogerio Licastro Torres de. Primeiros comentários ao novo Código de Processo Civil. São Paulo: RT, 2015.

Recebido em: 28/03/2018

Aprovado em: 26/04/2019 